\title{
Personality Characteristics in Patients with Phenylketonuria Treated Early ${ }^{1}$
}

\author{
J. WEGLAGE, A. RUPP. AND E. SCHMIDT

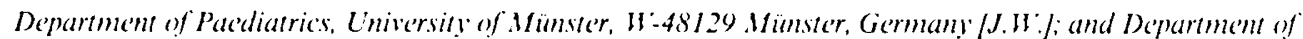 \\ Paediatrics, University of Heidelherg, W'-69120) Heidelherg, (iermany IA.R., E.S.I
}

\begin{abstract}
In the course of the German Collaborative PKU Study, the results of the Personality Questionnaire for Children (PFK 9-14) of 58 10-y-old patients treated early for phenylketonuria were analyzed. The main message of our data is that patients with phenylketonuria who were treated early and strictly did not show a higher risk for severe emotional and behavioral maladjustment compared with healthy controls at the age of $10 \mathrm{y}$. The patients were characterized only by "less masculinity of attitudes." Because no significant correlations were observed between the quality of dietary control and the results of the questionnaire, the noticed personality characteristic of the patients could be interpreted as a psychosocial consequence of the chronic discase. (Pediatr Res 35: 611-613, 1994)
\end{abstract}

Abbreviations

Phe, phenylalanine

$\mathrm{IQ}$, intelligence quotient

PKU, phenylketonuria

ANOVA, analysis of variance

Up to now only a few studies have dealt with the problem of emotional and behavioral consequences of PKU and its dietary treatment. Children with untreated PKU are typically described as hyperactive, erratic, and aggressive, often with temper tantrums, episodes of screaming, noisiness, and self-punitive behavior (1). Also, children with PKU and normal intelligence who are treated early are reported to have higher risk of psychopathologic disorders or emotional and behavioral difficulties such as mannerism, anxiety, depression, hyperactivity, and low frustration tolerance (2-9). They are also described as less autonomous, less self-confident, and more solitary and unhappy $(9,10)$.

Earlier studies on the topic of psychosocial maladjustment have varied extensively in design, methods, terminology, and results $(10)$. Findings of most studies are not comparable and generalizable because of severe methodologic problems such as small samples, missing control groups, inhomogeneity of patients concerning age and sex, and insufficient information concerning length and quality of dietary control (10). Most studies are based on outside observations by teachers, parents, or hospital staff (1$9,11)$. Only a few studies give an insight into psychic processes of the patients themselves (10). In general, epidemiologic studies and examinations of specific risk groups have demonstrated an increased incidence of psychologic maladjustment in children and adolescents with chronic diseases (12-16).

Received April 15, 1993: accepted December 7, 1993

Correspondence and reprint requests: Dr. Dr. Josef Weglage, Universitätskinderklinik, Albert-Schweitzer-Str. 33, 0251/837707, 48129 Munster Germany.

Supported by Bundesministerium für Forschung und Technologic (BMFT).

'This study was done on behalf of the German Collaborative PKU Study. Participating centers were Berlin. Düsseldorf, Hamburg. Heidelberg. Göttingen, München, Münster, and UIm.
In the literature, different hypotheses exist with regard to a higher rate of psychosocial maladjustment of patients with PKU. First, a neurobiochemical approach suggests that the direct effect of increased Phe levels on brain cells produces an impairment of brain protein synthesis, myelin turnover, and neurotransmitter amine synthesis (8). Second, the psychosocial approach emphasizes that the necessity of maintaining a highly artificial diet, regular blood tests, frequent visits to the hospital, and daily problems managing the diet may contribute to a higher frequency of psychosocial problems $(10,12,15,17)$. Moreover, the parents' perceptions and expectations of difficulties or restrictions associated with chronic diseases may provoke changes in the child's adjustment $(3,6,12-15)$. In addition the chronic disease, PKU may mislead parents into becoming overprotective and restrictive with their children, which is found to be a risk factor for psychosocial maladjustment (10).

In a prospective study of patients with PKU who were treated early, we attempted to give an introspective recording of psychic processes where an outside observation does not have access, for instance, to the patients' self-concept, needs, and motives. In addition, we tried to answer whether special aspects of emotional and behavioral development are associated with the quality of dietary control.

\section{MATERIALS AND METHODS}

In this study, data of 5810 -y-old patients with classic PKU who were treated early ( 30 girls and 28 boys) were investigated (18). The diet started on average at the $17 \mathrm{th}$ d of life $(\mathrm{SD}=7.7$; range, $7-45 \mathrm{~d}$ ).

The patients completed the Personality Questionnaire for Children (PFK 9-14) (16, 19), which gives insight into behavioral patterns, needs, motives, and self-concept of the patients. Out of the 15 primary factors, five superordinate secondary factors were built (Table 1). On the basis of factor analysis, the PFK 9-14 questionnaire was constructed by Seitz and Rausche "for an early identification of children with potentially behavioral and emotional disorders" $(16,19)$. The PFK $9-14$ is the most often used and best evaluated personality questionnaire for 9- to 14-y-old children in German-speaking countries $(10,16,19,20)$. It was developed in 1976 (19), and it was standardized and revised in 1992 (16). The following reliability scores were computed for the scales of the PFK 9-14: the split half-coefficients $r_{\mathrm{t}}$ according to Spearman-Brown ranged from 0.66 to 0.87 (mean $r_{\mathrm{u}}=0.76$ ) and the internal consistency scores $r_{\mathrm{tt} \ldots}$ according to Cronbach ranged from 0.67 to 0.87 (mean $r_{\mathrm{tt}-\mathrm{k}}=0.74$ ). The factor-analyzed PFK 9-14 only consists of items that had a communality greater than 0.1 and more than $50 \%$ of the communality on one factor. The five secondary factors were the result of a factor analysis based on the intercorrelations of all PFK scales (16). As an indication of validity the constance of factor intercorrelations and structure of factors were replicated for different populations (21-23). The PFK 9-14 was standardized separately for boys and girls and different age groups $(9,10,11,12,13$, and $14 \mathrm{y})$. 
Table 1. Personality Questionnaire for Children (PFK 9-14)

\begin{tabular}{|c|c|c|c|c|c|}
\hline & \multicolumn{2}{|c|}{$\begin{array}{l}\text { PKU group } \\
(n=58)\end{array}$} & \multicolumn{2}{|c|}{$\begin{array}{c}\text { Comparison } \\
\text { group } \\
(n=218) \\
\end{array}$} & \multirow[b]{2}{*}{$p^{*}$} \\
\hline & Mean & $\mathrm{SD}$ & Mean & SD & \\
\hline \multicolumn{6}{|l|}{ Behavioral patterns } \\
\hline Emotional sensitivity & 49.5 & 8.8 & 50.0 & 10.0 & NS \\
\hline Lack of will control & 48.1 & 11.0 & 50.0 & 10.0 & NS \\
\hline Extrovert temperament & 48.7 & 9.8 & 50.0 & 10.0 & NS \\
\hline Interpersonal behavior & 49.1 & 9.7 & 50.0 & 10.0 & NS \\
\hline \multicolumn{6}{|l|}{ Needs and motives } \\
\hline $\begin{array}{l}\text { Aggressive need for self-pres- } \\
\text { entation }\end{array}$ & 47.9 & 11.5 & 50.0 & 10.0 & NS \\
\hline $\begin{array}{l}\text { Need for autonomy and self- } \\
\text { sufficiency }\end{array}$ & 47.1 & 9.6 & 50.0 & 10.0 & NS \\
\hline Scholastic ambition & 49.8 & 10.3 & 50.0 & 10.0 & NS \\
\hline Social commitment & 50.4 & 8.3 & 50.0 & 10.0 & NS \\
\hline Dependency on adults & 49.2 & 10.3 & 50.0 & 10.0 & NS \\
\hline Masculinity of attitudes & 43.3 & 10.5 & 50.0 & 10.0 & 0.001 \\
\hline \multicolumn{6}{|l|}{ Self-image } \\
\hline General anxiety & 51.4 & 8.3 & 50.0 & 10.0 & NS \\
\hline Self-confidence & 52.6 & 8.3 & 50.0 & 10.0 & NS \\
\hline Impulsiveness/carefreeness & 50.5 & 9.3 & 50.0 & 10.0 & NS \\
\hline Self-deception & 52.6 & 8.0 & 50.0 & 10.0 & NS \\
\hline Feelings of inferiority & 47.6 & 9.1 & 50.0 & 10.0 & NS \\
\hline \multicolumn{6}{|l|}{ Secondary factors } \\
\hline Aggressive assertiveness & 48.4 & 10.0 & 50.0 & 10.0 & NS \\
\hline Social complacence & 51.9 & 9.3 & 50.0 & 10.0 & NS \\
\hline Emotionality & 49.4 & 8.5 & 50.0 & 10.0 & NS \\
\hline Self-sufficient isolation & 48.3 & 8.9 & 50.0 & 10.0 & NS \\
\hline Open-optimistic orientation & 51.9 & 8.3 & 50.0 & 10.0 & NS \\
\hline
\end{tabular}

* Two-sided $t$ test.

The control populations were representative for socioeconomic status and intelligence $(16,19)$. The patients with PKU were only compared with the 10-y-old male $(n=110)$ and female controls $(n=108)$.

IQ data for 52 patients were available and measured by the German version of the WISC-R at the age of $9 \mathrm{y}$. Annual medians were computed from quantitative measures of serum Phe concentrations, regularly registered on a monthly basis. The mean of the annual medians was taken as an index of dietary control.

Parametric tests ( $t$ test, ANOVA, product-moment correlation according to Pearson) were used for statistical evaluation of the data. For the medians of the serum Phe concentrations a cluster analysis according to MacQueen was computed. To evaluate the relationship between the PFK scores and the quality of dietary control two statistical procedures were used. First, correlations according to Pearson were computed to test the general relationship between the continuous variables: PFK scores and serum Phe levels. Second, ANOVA for the three subgroups of cluster analysis should reveal possible differences between the subgroups with "good," "intermediate," and "poor" dietary control. Twosided tests were computed. The $\alpha$-error was corrected according to Bonferroni.

\section{RESULTS}

Dietary control. According to the German Pediatric Society, serum Phe concentrations for patients with PKU younger than $10 \mathrm{y}$ of age should be below $363 \mathrm{mmol} / \mathrm{L} \mathrm{(24)}$.

Cluster analysis of the individual longitudinal Phe profiles revealed three clusters of different dietary control (Fig. 1): "good dietary control" cluster $(n=30)$ with mean Phe levels nearly or below $363 \mu \mathrm{mol} / \mathrm{L}$ all the time; "intermediate dietary control" cluster $(n=22)$ with Phe levels surmounting the critical level of $363 \mu \mathrm{mol} / \mathrm{L}$ at the age of $2 \mathrm{y}$ and approaching $606 \mu \mathrm{mol} / \mathrm{L}$ at the age of $9 \mathrm{y}$; and the "poor dietary control" cluster $(n=6)$ with Phe levels higher than $363 \mu \mathrm{mol} / \mathrm{L}$ after the age of $2 \mathrm{y}$, higher

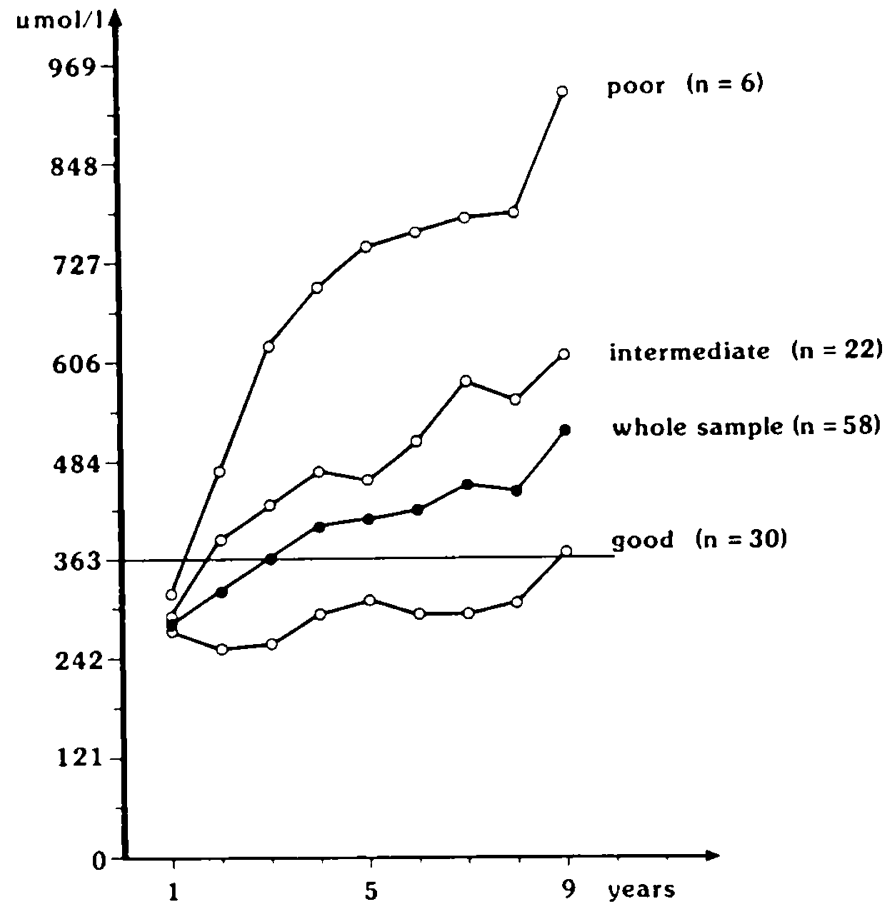

Fig. 1. Serum Phe concentrations: average of annual medians for the whole sample and the subgroups with good, intermediate, and poor dietary control. The horizontal line indicates the desired level.

than $606 \mu \mathrm{mol} / \mathrm{L}$ after $3 \mathrm{y}$, and ending up with $936 \mu \mathrm{mol} / \mathrm{L}$ at the age of $9 \mathrm{y}$.

$I Q$. A total of 52 patients were tested with the WISC-R. With a mean IQ of $96.4(\mathrm{SD}=12.8$; range, $70-122)$, the patients reached an intellectual performance within the normal range (mean $=100, \mathrm{SD}=15)$, but it was significantly below the mean IQ of the general population (mean $=100, \mathrm{SD}=15)(t$ test, $p<$ 0.05 ). Patients with poor (mean $=90.0 ; \mathrm{SD}=7.5$; range, $82-$ $102 ; n=5)$, intermediate $($ mean $=92.8 ; \mathrm{SD}=11.3 ;$ range, 70 $114 ; n=21)$, and good dietary control (mean $=100.7 ; \mathrm{SD}=$ 13.6; range, $70-122 ; n=26$ ) had significantly different mean IQ (ANOVA, $F=3.28, d f=2, p<0.05$ ).

Personality Questionnaire for Children (PFK 9-14). In comparison with healthy controls, the 58 patients with PKU only showed significantly less "masculinity of attitudes" (Table 1). Separate analysis confirmed this significant difference even for the boys' group $(n=28)$ and the girls' group $(n=30)$. No significant differences were observed between the results of the boys' group and the girls' group ( $t$ test, NS).

Relationships between personality characteristics and quality of dietary' control. No significant correlation could be computed between the scales of the PFK questionnaire and the average serum Phe concentration since birth for the whole group ( $n=$ $58)$ as well as for the boys' group $(n=28)$ and the girls' group (correlations according to Pearson, NS).

The three groups ("good," "intermediate," and "poor dietary control") did not differ significantly in their personality characteristics (ANOVA, NS).

\section{DISCUSSION}

In contrast to other studies, these results suggest that the patients with PKU treated early and relatively strictly do not show a higher risk for severe psychosocial maladjustment compared with healthy controls at the age of 10 y $(16,19)$. According to their own perception, these children can grow up without increased risks of behavioral and emotional disorders up to the age of $10 \mathrm{y}$.

One consequence of their experiences with their burdensome 
disease might be that they were more sensitive, empathic, and less "masculine in their attitudes." However, they did not believe they were inferior in their general abilities, and they experienced themselves as attractive as their peers. In contrast to other studies, our data do not show that boys were characterized by more severe personality problems than girls $(8,9,11)$.

There are several explanations for these surprising results. First, our patients are still children, and they are still living under the protection of their families. In addition to the burdensome diet, developmental crises like puberty may cause more severe emotional and behavioral problems as reported by Weglage $e t$ al. (10) for adolescent patients with PKU.

Second, participation in the German Collaborative PKU Study provides intensive medical and psychologic counseling for both the patients and the parents. They were seen at least twice a year, and in case of problems they were seen even more often. This treatment could be interpreted as a protective factor. Furthermore, increased experiences in treating patients with PKU might help not just the hospital staff but also patients and parents in their attitude that living with PKU is a more natural thing than it was 10 or $15 \mathrm{y}$ ago. An increased sovereignty in dealing with PKU probably reduces stress and consequently psychosocial maladjustment.

Third, different methods of examination may cause different results. In most studies, ratings by schoolteachers, parents, or hospital staff were used to characterize the psychosocial development of patients (3,5-9). Selective perception may influence these results. These individuals might know from the literature or hospital staff that the children have a certain risk for psychosocial maladjustment. On the other hand. it is true that selfratings by the patients-as used in our study-give an insight into psychic processes where outside observations do not have access, but this approach may cause a "super normal construction of personality" (10). In the first case the extent of personality problems possibly is overrated, whereas in the second case they probably are underestimated.

No significant correlations were observed between the results of the Personality Questionnaire for Children and the average serum Phe concentrations since birth. Furthermore, no significant differences were seen in personality characteristics between the three clusters of different dietary control. These results are arguments against the neurobiochemical hypothesis, at least for patients like those participating in our study with mean serum Phe levels below $909 \mu \mathrm{mol} / \mathrm{L}$. Elevated Phe levels may be more critical (10). Most of our patients reached serum Phe concentrations below those reported for patients of other studies $(3,5-9)$. However, the variance of serum Phe levels was small, and only six patients had a "poor dietary control." Possibly our patients were too young, and a relationship between serum Phe levels and personality characteristics may occur when children get older.

Weglage et al. (10) have demonstrated the importance of psychosocial conditions for the quality of dietary control and the psychological development for adolescents with PKU (10). In the German Collaborative PKU Study both patients and parents received intensive psychologic care. As a consequence, more effective coping strategies in dealing with the disease and dietspecific problems probably reduced the frequency of psychologic problems (10). In special cases, social counseling programs and psychotherapy should be offered to parents and patients continually from soon after birth.

The question remains whether "less masculinity of attitudes" is a specific personality characteristic of patients with PKU. We do not know for sure, but we believe not. The characteristic could be interpreted as a consequence of chronic diseases in general (10). The question whether and how the patients develop specific to their PKU can be answered by comparative studies of patients with other chronic diseases like diabetes. The question whether the rate of emotional and behavioral disturbances will increase when the child gets older should be answered by repeated examinations at appropriate ages. Both questions will be examined in the German Collaborative PKU Study. The main message of our study is that 10 -y-old patients with PKU perceive themselves as quite normal with regard to their personality development. It is an important but one-sided result. Further studies should also concern themselves with the reports of persons to whom the children relate most closely because all these people can rate different aspects of psychosocial development, which may all be important for the research question. The studies will provide information not only for patients with PKU but also for patients with other chronic diseases $(10,12-15,17,20)$.

Acknowledgments. The authors thank Prof. Dr. K. Ullrich from the University of Münster and Dr. P. Burgard from the University of Heidelberg for their helpful cooperation.

\section{REFERENCES}

1. Wood AC, Friedmann CJ, Steisel IM 1967 Psychological factors in phenyilketonuria. Am J Orthopsychiatry 37:671-679.

2. Holtzman N. Richard M. Kornmal A 1986 Effect of age at loss of dietary control on intellectual performance and behavior of children with phenylketonuria. N Engl J Med 314:593-598

3. Kazak AE. Reber M. Snitzer L 1988 Childhood chronic disease and family functioning. A study of phenylketonuria. J Pediatr $81: 224-230$

4. Moon JL. Wilcox RD, Burns JK 1977 PKU as a factor in the development of self-esteem. J Men Defic Res 90:1027-1029

5. Realmuto G. Garfinkel BD. Tuchman M. Tsai MT. Chang PN. Fisch RO, Sharpio S 1986 Psychiatric diagnosis and behavioral characteristics of phenylketonuric children. J Nerv Ment Dis 174:536-540

6. Reber M, Kazak AE, Himmelberg P 1987 Phenylalanine control and family functioning in early treated phenylketonuria. Dev Behav Pediatr $8: 311-317$

7. Schor DP 1986 Phenylketonuria and temperament in middle childhood. Winter-Press 14:163-167

8. Smith 1. Beasley MG, Wolf OH, Ades AE 1988 Behavior disturbances in 8year-old children with early treated phenylketonuria. J Pediatr 112:403-408

9. Stevenson JH, Hawcroft J, Lobascher M. Smith I. Wolf OH, Graham PJ 1979 Behavioral deviance in children with early detary treated phenylketonuria. Arch Dis Child 54:14-18

10. Weglage J, Fünders B, Wilken B. Schuber D. Schmidt E, Burgard P. Ullrich $K 1992$ Psychological and social findings in adolescents with phenylketonuria. Eur J Pediatr 151:522-525

11. Fisch RO. Sines LK, Chang P 1981 Personality characteristics in non-retarded phenylketonurics and their family members. J Clin Psych 42:106-113

12. Angermeyer MC. Döhner O (eds) 1981 Chronisch kranke Kinder und Jugendliche in der Familie. Enke, Stuttgart

13. Drotar D 1981 Psychological perspectives in chronic childhood illness. J Pediatr Psychol 6:211-228

14. Hiser C 1985 The Psychology of Childhood Illness. Springer, Berlin

15. Petermann F. Nocker M, Bode U 1987 Psychologie chronischer Krankheiten im Kindes- und Jugendalter. Psychologie Verlags-Union. Munchen, Germany

16. Seitz W. Rausche A 1992 Persönlichkeitsfragebogen für Kinder (PFK 9-14). Westermann-Verlag. Braunschweig, Germany

17. Awiszus D. Unger I 1990 Coping with PKU: results of narrative interviews with parents. Eur J Pediatr 149(suppl 1):45-51

18. Blascovies ME. Schemer GE. Hack S 1974 Phenylalaninemia. Differential diagnosis. Arch Dis Child 49:835-843

19. Seitz W. Rausche A 1976 Persönlichkeitsfragebogen für Kinder (PFK 9-14). Westermann-Verlag. Braunschweig, Germany

20. Kramer HH, Awiszus D, Sterzel U, v. Halteren A. Claßen R 1989 Development of personality and intelligence in children with congenital heart disease. $J$ Child Psych Psychiat 30:299-308

21. Littmann F: 1986 Entwicklung. Validierung und Normierung zweier Sclbstbeurteilungsbögen (PF/SF) zur Diagnostik sozial-charakteristischer Eigenschaften. Verhaltensauffalligkeiten und Fehlentwicklungen im Schulkindalter. Thesis, University of Jena, Germany

22. Seitz. W, Hansen G 1992 Spontanmotorik und Personlichkeit bei Kindern. In: Seitz A. Rausche A (eds) Persönlichkeitsfragebogen für Kinder PFK 9-14. Westermann-Verlag. Braunschweig. Germany

23. Kühn R 1983 Zur Faktorenstruktur des Persönlichkeitsfragebogens fur Kinder 9-14 von $W$. Scitz und $A$. Rausche. Mitteilungen und Nachrichten des Deutschen Instituts fur Internationale Padagogische Forschung. No. 110/ 111, pp 91-98

24. German Pediatric Society 1990 Limits in serum phenylalanine concentrations of different ages. Convention of the Deutsche Arbeitsgemeinschaft für Pädiatrische Stofliechselerk rankungen. Monatschr Kinderheilk 138:636 